
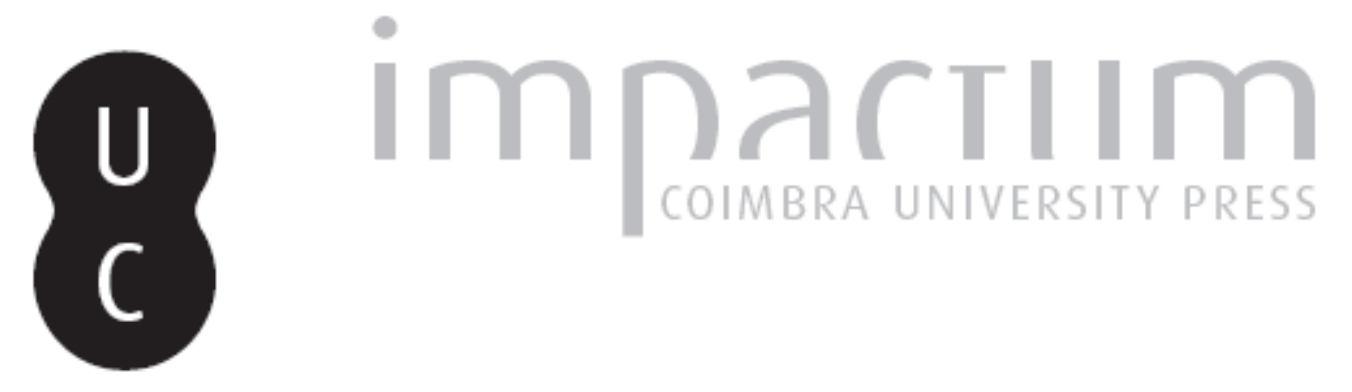

\title{
As cidades «bíblicas» de Pi-Ramsés e Pi-Atum
}

\section{Autor(es): $\quad$ Camacho, João Paulo}

Publicado por: Centro de História da Universidade de Lisboa

URL persistente:

URI:http://hdl.handle.net/10316.2/23720

DOI:

DOI:http://dx.doi.org/10.14195/0871-9527_20_8

Accessed : $\quad$ 26-Apr-2023 09:14:52

A navegação consulta e descarregamento dos títulos inseridos nas Bibliotecas Digitais UC Digitalis, UC Pombalina e UC Impactum, pressupõem a aceitação plena e sem reservas dos Termos e Condições de Uso destas Bibliotecas Digitais, disponíveis em https://digitalis.uc.pt/pt-pt/termos.

Conforme exposto nos referidos Termos e Condições de Uso, o descarregamento de títulos de acesso restrito requer uma licença válida de autorização devendo o utilizador aceder ao(s) documento(s) a partir de um endereço de IP da instituição detentora da supramencionada licença.

Ao utilizador é apenas permitido o descarregamento para uso pessoal, pelo que o emprego do(s) título(s) descarregado(s) para outro fim, designadamente comercial, carece de autorização do respetivo autor ou editor da obra.

Na medida em que todas as obras da UC Digitalis se encontram protegidas pelo Código do Direito de Autor e Direitos Conexos e demais legislação aplicável, toda a cópia, parcial ou total, deste documento, nos casos em que é legalmente admitida, deverá conter ou fazer-se acompanhar por este aviso.

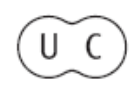




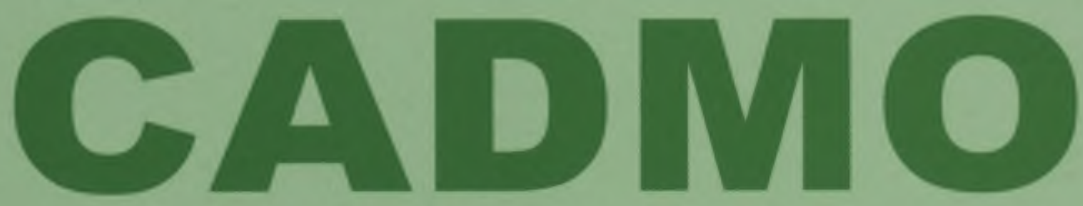

Revista de História Antiga

\author{
Centro de História \\ da Universidade de Lisboa
}

\title{
20
}

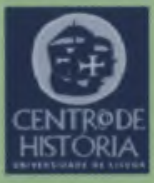

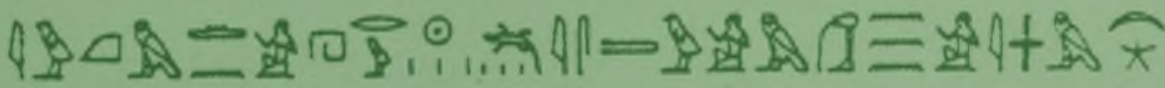

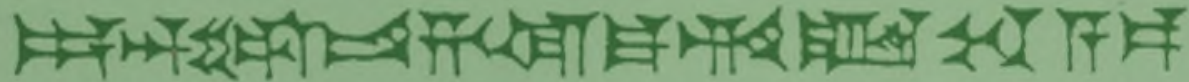

MHNIN AEI $\Delta$ E $\Theta E A ~ \Pi H \Lambda H I A \triangle E \Omega$ 


\title{
AS CIDADES «BÍBLICAS» DE PI-RAMSÉS E PI-ATUM
}

\author{
JOÃO CAMACHO \\ Universidade de Lisboa \\ joaocamacho@msn.com
}

\section{Objectivos do trabalho}

O presente trabalho visa caracterizar, de forma sucinta, as "cidades bíblicas" de Pi-Ramsés e Pi-Atum, seguindo essencialmente dois eixos: o da história da descoberta e identificação arqueológica dos locais e o da caracterização do espaço físico, relevando a importância política e económica de ambos.

Um tema desta natureza implica uma movimentação inevitável e parcial em terrenos da arqueologia, o que será feito com o cuidado que tal tarefa exige de um não-arqueólogo.

A questão da localização de Pi-Ramsés e Pi-Atum tem sido um dos assuntos mais discutidos desde o início da egiptologia e, certamente, um dos mais polémicos. Para começar, a arqueologia do Delta esteve durante muito tempo menos desenvolvida que a do resto do Egipto, em virtude de uma certa inadequação dos métodos conhecidos, que aumentavam as dificuldades dessas empresas e empurravam os arqueólogos para sul. Por outro lado, foram notórias algumas deficientes e até precipitadas interpretações, próprias de um processo de crescimento da disciplina. Inerente a alguns destes problemas, e como adiante veremos, esteve o peso da tradição bíblica.

Até ao início do século $\mathrm{XXI}$, o debate não estava completamente encerrado. Contudo, é quase unânime a concordância dos estudiosos em reconhecer na actual região de Qantir a antiga Pi-Ramsés. Quanto a Pi-Atum, muitas dúvidas subsistem quanto à sua localização precisa, no entanto parece certo que esta se posicionava na região do Uadi Tumilat. 


\section{Contexto histórico, delimitação temporal e panorama geográfico}

O período cronológico explorado no presente trabalho é aquele que corresponde grosso modo à fase de domínio hicso no Baixo Egipto, durante o qual a região do Delta Oriental conhece um maior desenvolvimento, até meados da XX dinastia, altura em que a cidade de Pi-Ramsés começa a perder preponderância política e económica, até ao seu abandono temporário.

O rio Nilo divide-se hoje no Delta em dois braços fluviais, o de Damieta e o de Roseta, num local a aproximadamente $20 \mathrm{~km}$ a norte do Cairo. Porém, na Antiguidade existiam sete braços: o pelúsio, o tanítico, o mendesiano, o fanítico, o sebenítico, o bolbítico e o canópico. No Delta, o esteiro mais oriental era o braço do Pelúsio, que derivava para nordeste desde a região perto de Heliopólis e desaguava na baía com o mesmo nome, já no nordeste do Sinai. Em tempos pré-históricos existiu outra sub-divisão nilótica, que atravessava o deserto oriental, mais demarcadamente a partir de Bubástis até às depressões a norte de Suez, até ao lago Timsah. O desaparecimento desta extensão permitiu o aparecimento de uma zona fertilizada no local do antigo curso, ao qual se deu o nome de uadi Tumilat. De resto, o estudo da geologia da região envolvente, e a própria topografia (as "ilhas de areia»), revelam que, no processo de formação do rio Nilo, foram vários os braços fluviais existentes durante as várias etapas desse processo.

O Delta Oriental era uma região de grande importância, nomeadamente pela posição geográfica que o colocava como zona fronteiriça do Próximo Oriente, com o qual o Egipto sempre se relacionou política e economicamente (principalmente). Essa importância ganhou uma nova dimensão no período estudado. Primeiro, os Hicsos mantiveram relações privilegiadas com várias regiões asiáticas, como prova a sua fixação em Auaris, nas margens, e sensivelmente a meio, do braço nilótico pelúsio, perto da actual Tell ed-Daba. A região foi dinamizada neste período (fase da primeira ocupação de Tell el-Maskhuta) e continuaria a sê-lo no Império Novo, já que as convulsões bélicas que resultaram na expulsão e perseguição dos governantes hicsos até à Ásia despoletaram um interesse objectivamente mais político/militar sobre este territórios e, consequentemente, uma maior atenção sobre as estruturas aí existentes.

Neste âmbito, podemos relevar a existência das duas localidades do tema do trabalho, a da referida Auaris, que continuou a ser ocupada (após a queda da resistência dos hicsos), Silé, Migdol, entre outras. 
Toda esta região, no Império Novo, estava sob forte controlo central, não obstante as reformas administrativas da XVIII dinastia, pois, mais do que nunca, os antigos Egípcios perceberam a dimensão do perigo, já que estiveram, pela primeira vez, subordinados a um poder estrangeiro, asiático, durante mais de um século.

É este facto que, em grande medida, vinca um dos traços mais marcantes, senão mesmo o mais importante, do Egipto do Império Novo: uma sociedade militarizada, cosmopolita, arrojada e auto-convencida da sua superioridade cultural, mas sem nunca perder o seu espírito tolerante que ajuda a moldar uma forma de governo que vários autores classificam como «imperialismo egípcio».

\section{Desenvolvimento}

O conhecimento do Delta, relativamente ao antigo Egipto, está bastante mais incompleto que o do restante vale nilótico(1). A sua composição pantanosa, como já referimos, afugentou muitos arqueólogos para os terrenos secos do sul. Contudo, não será preciso recorrer à arqueologia para perceber a importância das suas localidades, desde o Império Antigo, como vem demonstrado nos textos (nomeadamente no que diz respeito a cidades como Buto, Sais, Busíris ou Iseum). O Delta era uma região que proporcionava fáceis comunicações latitudinais, devido à navegabilidade dos seus vários braços, mas que longitudinalmente oferecia muitos problemas às deslocações, principalmente tendo em conta que estas se faziam preferencialmente a pé, de burro ou de boi, por terrenos intra-fluviais que eram sobretudo adequados à agricultura em pequena escala ${ }^{(2)}$.

O Egipto era um país construído de sul para norte. Apesar da unidade política, era reconhecida a ambivalência da sua composição, como prova a designação de Duas Terras, Taui, que integrava a titulatura régia e que expressava precisamente essa distinção. Por outro lado, a geografia transmite outra evidência: rodeados de deserto, e no contexto civilizacional pré-clássico, era no Norte que existiam os canais de contacto com o exterior, nomeadamente com a Ásia (principalmente) e com a Grécia micénica, ou mais tarde a helenística. Isto porque no Sul, e sobretudo nos períodos politicamente mais fortes, os núbios e as suas estruturas sociais menos complexas nunca ofereceram uma verdadeira resistência. De resto, à semelhança do que sucedeu a norte com os Hicsos, o emergente perigo núbio foi, no ínicio do Império Novo, 
completamente destruído e as suas estruturas políticas substituídas por outras de origem egípcia. Na mesma linha, e apesar de considerados menos preocupantes(3), estavam os Líbios, povo de pastores semi-nómadas, desde cedo subjugados ao poder central egípcio.

As relações externas egípcias eram pautadas principalmente pelo interesse em matérias-primas das quais o país fosse deficitário. A principal era madeira de qualidade, como a de cedro que, pelo menos desde a Época Tinita, vinha da região do actual Líbano. Outras madeiras como a de carvalho, freixo, faia ou videiro, vinham da Ásia Menor. Para além de uma série de produtos mais luxuosos, como o lápis-lazúli, outros materiais muito apreciados, como a prata ou o cobre, vinham de diferentes regiões asiáticas. Eram milenares e regulares os contactos comerciais com as cidades-estado da Síria-Palestina, que por sua vez funcionavam como entrepostos para produtos de várias proveniências beneficiando de uma posição geográfica que as punha em contacto com praticamente todo o mundo civilizado.

Por outro lado, a sua existência em territórios marginais aos dos vários reinos emergentes (como o de Hattucha, de Nínive ou da Babilónia) colocou cidades como Guezer, Meguido ou Hazor em permanentes duelos políticos, criando intrincadas redes de relações de poder entre elas que, simultaneamente, impediam uma unidade política e as deixava mais vulneráveis a ataques exteriores ${ }^{(4)}$.

No que diz respeito a essas relações, as políticas egípcias do Império Novo diferem bastante das que foram seguidas em períodos anteriores, assumindo uma postura objectiva de força, na sequência do domínio e expulsão dos Hicsos, ou dos "chefes de terras estrangeiras»(5) Não nos iremos debruçar muito sobre este tema, porém, são as conquistas militares egípcias no Próximo Oriente que relevam a importância das cidades do Delta Oriental, na medida em que estas se tornaram em pontos de apoio logístico fundamental para o envio e recepção de expedições, por um lado, e para o crónico problema da indesejável vizinhança de populações semi-nómadas, por outro(6).

\section{A questão bíblica}

As referências bíblicas às localidades de Ramsés e Pitom (Êx. 1:11) são muito importantes porque, à partida, remetem para duas realidades históricas objectivas e que, no contexto exodal, contrastam com a restante narrativa, já que os outros elementos ali referidos são 
apenas historicamente contextualizáveis e não verificáveis. Assim, a identificação arqueológica destes dois locais assumiu especial importância, tendo sido objecto de longas discussões desde o século XIX, facto ilustrado pela própria história da descoberta, que veremos adiante.

São reconhecidos variados elementos semitas, existentes no Delta Oriental, sobretudo a partir de meados do Império Novo. A literatura também regista a crescente infiltração, que culminará com a conquista do poder, aparentemente pacífica, por parte dos Hicsos. A existência de populações cananaicas era inquestionável e consequência de uma atracção exercida pelo país do Nilo com todas as suas riquezas, sobre as gentes de Leste. Porém, pelo menos duas questões prévias se colocavam aos investigadores.

Em primeiro lugar, a arqueologia, durante algum tempo e à semelhança de outras disciplinas, tomou a narrativa bíblica de forma literal, seguindo, erradamente, textos de objectividade dúbia, escritos muito tempo depois dos acontecimentos narrados com base em relatos pré-literários ${ }^{(7)}$, induzindo em erro os arqueólogos.

Em segundo lugar, e relacionado com o ponto anterior, está a própria análise linguística às referências. $O$ termo que se traduz para português como "cidades-depósito", é um termo hebraico e não egípcio, que implica a existência de determinadas estruturas, que se assemelhem de alguma forma nos dois contextos. Esta discussão gerou conclusões algo divergentes, mas que actualmente estão praticamente ultrapassadas. O arqueólogo John S. Holladay considerou que tal designação era atribuída a locais cuja importância derivava essencialmente de grandes estábulos. Por outro lado, arqueólogos sírio-palestinianos como James B. Pritchard, entenderam o termo de uma forma mais literal, considerando por isso que o nome derivava mesmo de grandes depósitos (mantimentos, armas). James K. Hoff́meier comparou a disposição urbana de cidades bíblicas como Meggido e Hazor, às quais foram atribuídas também a designação de "cidades-depósito", com cidades egípcias como Tebas e com a própria constituição de alguns templos, concluíndo que tanto estábulos como centros administrativos eram elementos comuns às duas realidades. Esta teoria era reforçada pela preferência dos egípcios em utilizar tijolos de adobe, cuja produção foi atribuída aos hebreus ${ }^{(8)}$. É igualmente importante compreender que, tanto Ramsés como Pitom, devido à não utilização da forma $\mathrm{Pi}$ ( $\mathrm{Pr}=$ casa) e da referida distanciação literária, podem ser referências mais simbólicas do que precisas, podendo, neste sentido, referir-se a uma região, a uma cidade ou a um templo(9). 
Foi neste sentido que Donald B. Redford, já após a identificação de "Ramsés" com Qantir, formula uma contestação baseada precisamente nessa ausência do vocábulo prefixal $\mathrm{Pi}$ ou $\mathrm{Pr}$ no texto bíblico(10). Refere também que a tradução do duplo $S$ em Ramesse era um fenómeno linguístico hebraico pós-saíta, acentuando assim o carácter anacrónico do nome exodal. Porém, Wolfgang Helck demonstra que a não utilização do pr era recorrente em textos coevos, e descobre vários exemplos de transposições linguísticas semelhantes, provando que não era um pormenor exclusivo do período pós-saítico(11). Alguns decénios depois, Lemchte retoma uma possibilidade de anacronismo dos escritores bíblicos pós-exílio, procurando provar que, nesse período, Tânis era conhecida por Ramsés ${ }^{(12)}$. Contudo, a antiga Djanet dos egípcios era conhecida por Tânis, tal como vem referido n'Os Sal$\operatorname{mos}(78: 12-43)^{(13)}$.

\section{Pi-Ramsés}

A cidade de Pi-Ramsés, ou mais precisamente "Casa de Ramsés, Amado de Amon, Grande em Vitórias", foi uma das mais importantes do Império Novo. Construída por Ramsés II, a cidade granjeou grande importância e reputação nos seus cerca de duzentos anos de ocupação(14). Actualmente fica na zona da aldeia de Qantir, a $100 \mathrm{~km}$ a nordeste do Cairo e a $80 \mathrm{~km}$ a ocidente de Suez, na antiga margem esquerda do braço fluvial pelúsico, entre Bubástis e Tânis.

A identificação definitiva de Pi-Ramsés com Qantir decorreu dos achados do arqueólogo egípcio Mahmud Hamza, nomeadamente vários óstracos com o nome da cidade, assim como as estruturas de um palácio real. Porém, este foi o resultado de um processo sinuoso que se iniciou em 1886, quando o arqueólogo inglês Francis L.I. Griffith, ao serviço da Egyptian Antiquities Organization, colaborando com uma missão austríaca e com o Museu Pelizaeus, identifica o tell e procede às primeiras escavações ${ }^{(15)}$. Não obstante estes avanços, Flinders Petrie advogava que Pi-Ramsés seria no uadi Tumilat ${ }^{(16)}$, na actual Tell el-Retabah, enquanto que Alan Gardiner defendia a sua localização no Pelúsio, posição que de resto abandonaria ${ }^{(17)}$, após as escavações de Pierre Montet em Tânis.

As descobertas deste arqueólogo francês convenceram vários grandes egiptólogos, devido às suas aparentes evidências. Justificada a questão linguística, Montet revela diversas referências a Ramsés II e III 
encontradas na estatuária, assim como vestígios de obras arquitectónicas destes dois faraós, incluíndo indícios de um palácio ${ }^{(18)}$. Herman Kees, na sua obra de 1961, reforça a ideia, afirmando que a cidade havia sido conquistada aos Hicsos e que, desde então, havia mantido um ambiente cosmopolita particular, que permitiu a introdução de divindades asiáticas ${ }^{(19)}$. Porém, o tempo e o trabalho arqueológico revelaram um duplo engano do arqueológo francês: não só a cidade de Tânis não remontava ao Império Antigo (Ramsés reutilizou diversos elementos de localidades vizinhas) como uma análise cuidada à estratigrafia obrigou que se concluísse que a cidade não existia no reinado de Ramsés $\|^{(20)}$.

O desvio das atenções para sul, até à região de Qantir (entre Qantir e El-Khatana) foi promovido pelos trabalhos de arqueólogos como Labib Habachi, William Hayes e Shenata Adam. Actualmente, o local é estudado por uma equipa austríaca, liderada por Edgar B. Pusch (21), que intregra um projecto do Museu Pelizaeus de Hildesheim.

A cidade de Pi-Ramsés foi erigida por ordem do faraó Ramsés II, com a intenção de formar aí a residência real no Delta. Esta não era uma iniciativa nova, pois alguns anos antes Akhenaton tinha feito 0 mesmo no Médio Egipto com a construção de Amarna. Porém, e como demonstra a estratigrafia do local ${ }^{(22)}$, a cidade de Pi-Ramsés manteve-se activa durante mais de dois séculos, ao contrário dos cerca de quinze anos de Akhetaton.

Actualmente, a cidade só tem sido parcialmente escavada, pois os terrenos agrícolas que cobrem parte do local são bastante férteis, facto que dificulta a sua exploração. Contudo, aqueles que estão disponíveis são igualmente muito fecundos arqueologicamente ${ }^{(23)}$, tendo já fornecido vestígios de estábulos, salas hipostilas, soalhos, vestígios de estatuária com inscrições, fundições de metais e pilares de um palácio real.

Como se pode verificar na imagem que acompanha este artigo, a cidade ficava semi-rodeada por canais nilóticos, ao longo dos quais se estendiam os subúrbios e estava dividida por quatro centros administrativos $^{(24)}$ : na zona sul, e mais perto da actual El-Khatana, estava o templo de Set (construído pelos Hicsos), a norte o templo de Nebeheh, a leste o de Astarte, e a oeste o de Amon ${ }^{(25)}$. Os edifícios centrais, administrativos e religiosos, situavam-se no centro, indicados no mapa pela legenda "CC" (p. 163).

O local arqueológico está dividido em várias zonas, sendo as de maior relevo histórico as divisões Q I e Q IV. 
$\mathrm{Na}$ zona $\mathrm{Q}$ I, a norte (estrato $\mathrm{B} 2$ ), foram encontrados vestígios do período ramséssida, como punhais, lanças, pontas de setas, armaduras, cavilhas, um travão(26) e outros de produção ou estilo asiático, como moldes de pedra hititas, para jantes, que provam a existência de um enorme campo de bigas. A grande quantidade de objectos estrangeiros, como olaria micénica, cipriota e levantina, indica também as estreitas relações dos egípcios com o exterior, nomeadamente nesta cidade, podendo ter funcionado também como centro diplomático, onde os embaixadores eram recebidos e colocados durante a sua estadia no país ${ }^{(27)}$. O estrato B3 revela uma imensa quantidade de artefactos relacionados com a produção de bronze ${ }^{(28)}$. A dimensão desta indústria indica que devia ser economicamente muito importante, podendo empregar centenas de pessoas.

$\mathrm{Na}$ zona de Q IV existia um monumental estábulo de ímpares dimensões (cerca de $15.000 \mathrm{~m} 2$ ). Dividia-se em seis áreas de doze divisões cada e tinha capacidade para cerca de 460 cavalos e respectivos tratadores. Foram encontrados vários objectos relativos à actividade, como arreios e cangas, muitos revestidos de ouro ou decorados com pedras semi-preciosas. Na mesma estrutura foram escavados pátios, com colunas palmiformes, pelos quais passavam sistemas de escoamento de dejectos animais. A qualidade e dimensão dos achados, aliados à informação existente em textos egípcios, levam à conclusão que se tratava de uma cavalariça real e de um armazém de arsenal militar.

Outras estruturas, como o palácio real ou o templo de Amon-Ré, continuam a ser escavados, mas, pela sua dimensão e pelo próprio carácter político da cidade, julga-se que possuíam grande importância e prestígio.

Quanto ao tamanho total da cidade, várias dúvidas subsistem, como prova a discordância, nesta matéria, entre Eric Uphill e Edgar B. Pusch. Enquanto o primeiro autor refere uma área aproximada de $15 \mathrm{~km} 2$, o segundo refere o dobro. Porém, desde 1996 que esses limites estão a ser investigados pela Bayerisches Landesant Für Denkmalpflege, em colaboração com outras entidades, utilizando o método Smart SM46, que consiste na medição dos níveis de césio dos tijolos de adobe. O agrupamento de tijolos com níveis semelhantes permitirá definir os limites não só da cidade, mas também do palácio, jardins, ruas, canais, etc. ${ }^{(29)}$

Para além desta questão, a prioridade é a identificação da funcionalidade de diversos edifícios oficiais. 


\section{Pi-Atum}

Pi-Atum é outra localidade egípcia referida no Êxodo (2:11), e que signifca "Casa de Atum". À semelhança do sucedido com Pi-Ramsés, a sua identificação gerou variadas discussões mas, ao contrário da primeira, a sua localização exacta permanece hoje duvidosa. John S. Holladay afirma que Pi-Atum se situava na actual Tell el-Maskhuta, na região do uadi Tumilat ou Tjeku (a bíblica Sucot) ${ }^{(30)}$. Este local arqueológico foi identificado por Edouard Naville(31), que defendeu logo ser essa a cidade exodal. Flinders Petrie seguiu essa teoria, ao mesmo tempo que defendeu que Pi-Ramsés se situava em Tell el-Retaba, a $14 \mathrm{~km}$ a oeste de El-Maskhuta. Mais tarde, Alan Gardiner e outros, influenciados pelas descobertas arqueológicas em El-Retaba, que abundantemente referiam o nome do deus Atum, viram-se tentados em considerar esta hipótese, algo a que prudentemente renunciaram devido à inexistência de provas inegáveis ${ }^{(32)}$.

Nos anos 70 do século passado, Hans Göedicke descobre uma estrutura defensiva em Tell el-Retaba. Baseando-se na leitura do Papiro Anastasi VI, que indica a existência de uma fortaleza na localidade que o autor julgou ser a Pitom do Êxodo, o arqueólogo austríaco defende que a existência de duas estruturas semelhantes em espaços tão próximos era pouco razoável. Por outro lado, James K. Hoffmeier relembra que ambas as localidades eram "cidades-depósito", designação que compreendia outras características, como já vimos, e que divergiam dessa interpretação.

Em 1967, Eric Uphill sugeriu a alternativa Heliópolis, com base na ideia de ser esta a cidade de Atum $^{(33)}$. Porém, não se conhecem referências egípcias semelhantes à cidade e mesmo na Bíblia esta é chamada de On (Gen. 41:45; Ezeq. 30:7). O director da equipa da Universidade de Toronto, John S. Holladay, que explora actuamente 0 local, defende, com base em diversas inscrições encontradas, que Tell el-Maskhuta era a Pitom bíblica(34). Nesta localidade existiu uma pequena povoação fundada no Segundo Período Intermediário e da qual se desconhece o nome original.

Foram encontradas construções erigidas em seis diferentes fases, sendo as mais importantes as localizadas na terceira, onde se identificou um aglomerado com pouco mais de 2 ha. 2 correspondendo a um espaço de ocupação sazonal e cujas principais actividades eram o comércio e a agricultura. Foram encontrados vários silos circulares, vestígios de trigo e de cevada (a agricultura era, no entanto, uma 
actividade invernal), assim como ossos de ovelhas, porcos, burros, cabras e pelo menos de um cavalo, em estruturas domésticas associadas a casas. A progressiva existência quantitativa destes elementos de fauna doméstica, levou a que se concluisse que houve uma ocupação efectiva, em fases mais tardias. Vestígios de caça (como avestruzes e gazelas) indicam a existência de savanas semi-áridas nos territórios circundantes, nas quais se formavam, temporariamente, pequenos lagos e pântanos. Existem também vestígios de produção de cerâmica e de fundições de cobre: em sinais desta natureza, foram reconhecidas influências egípcias, mas sobretudo sírio-cananaicas (Bronze Médio), com reconhecíveis semelhanças aos elementos cerâmicos oriundos de Tell el-Retabah (que, no entanto, incluíam exemplos mais sofisticados). Economicamente, é provável que a aldeia fosse subsidiária de Auaris $^{(35)}$, uma vez que os vestígios materiais não são particularmente exuberantes. Aliás, Carol Redmount, directora das várias expedições canadianas no país, defende que a região aquartelava os vários grupos étnicos semitas (consequência de eventuais decisões políticas), indivíduos que maioritariamente se dedicavam à pastorícia e que permaneceram no país após a expulsão dos Hicsos $^{(36)}$.

Segundo John S. Holladay, Pi-Atum era um entreposto comercial importante, que apoiava o comércio caravaneiro com a Arábia e com a Etiópia (Punt?), desde o período hicso e numa época em que os níveis do Nilo não permitiam que a navegação chegasse a Auaris. A comprovar esta teoria estão os vestígios de luxuriantes produtos asiáticos, que chegavam nas caravanas vindas de Leste e que contrastam com a pobreza dos vestígios dos subúrbios. Nas XVIII e XIX dinastias, os faraós voltam a ocupar a região. Contudo, os achados desse período indicam que essa ocupação implicou a utilização de materiais de outros locais ${ }^{(37)}$, o que, de resto, era uma prática muito comum não só nesta fase.

O local foi abandonado no fim da XX dinastia, e só voltaria a ganhar importância no reinado de Necau II, com a abertura de um canal entre o mar Vermelho e o mar Mediterrânico.

\section{Conclusão}

A procura da localização concreta das localidades de Pi-Ramsés e de Pi-Atum teve e tem especial interesse para os estudiosos do mundo pré-clássico, na medida em que são duas das mais importantes refe- 
rências históricas concretas contidas no livro do Êxodo, alargando a questão ao universo religioso. A arqueologia é uma disciplina central em questões desta natureza, pois qualquer interpretação de provas depende directamente dos seus resultados.

Em Qantir, as escavações deparam-se com problemas de vulto, nomeadamente a existência de diversas aldeias em redor que cobrem grande parte do anterior território de Pi-Ramsés e que, naturalmente, impossibilitam uma exploração de maior envergadura. Por outro lado, a sua efémera ocupação levou a que grande parte dos seus materiais tivessem sido levados para outros sítios (como duas estátuas colossais de Ramsés, encontradas em Tânis, que estariam à entrada do Templo de Amon, em Pi-Ramsés). Os avanços mais relevantes têm sido conseguidos nas últimas décadas com o imperioso recurso à tecnologia. Para além do já referenciado método Smart SM46, decorre um projecto que visa criar um mapa computorizado das estruturas subterrâneas, a partir da medição e agrupamento de impulsos electromagnéticos. Infelizmente, este é um processo moroso que, nas condições actuais, demorará mais alguns anos a concluir. Não obstante esta dificuldade, salientamos a descoberta de uma oficina de fundição de vidro, com diversos elementos que permitiram conhecer bem o faseamento deste processo(38).

Relativamente a Tell El-Maskhuta, a informação existente sobre as descobertas no local são bastantes mais escassas, sobretudo porque há vários anos que não são noticiados avanços.

A exegese bíblica possui uma historicidade que influenciou naturalmente este tema. No entanto, contrastando com a restante acção exodal, as cidades de Pi-Ramsés e Pi-Atum, desde que se admita que correspondam a Ramsés e Pitom, respectivamente, oferecem uma tangibilidade histórica de um nível muito diferente do que existe na restante narrativa. Neste âmbito, e à luz dos conhecimentos actuais, podemos afirmar que essa correspondência é bem correcta, no que concerne à localização de Pi-Ramsés. Quanto a Pi-Atum, as conclusões são mais discutíveis.

\section{Notas}

(1) Veja-se, para o efeito, a composição da obra de John BAINES e Jaromir MÁLEK, Egipto - Templos, Deuses e Faraós: apenas 11 páginas dedicadas ao Delta (pp. 166-177) para 49 do Alto Egipto (pp. 79-119) e 45 para o restante território (pp. 71-165).

(2) Hermann KEES, Ancient Egypt: a Cultural Topography, p. 120. 
(3) José das Candeias SALES, “Líbios", pp. 495-497.

(4) Bruce TRIGGER distingue o caso das cidades-estado gregas. A geografia política deste território permitiu o seu desenvolvimento, em competição é certo, mas beneficiando da ausência de poderes superiores nas vizinhanças. Daí que, uma vitória militar semelhante às das cidades-estado gregas frente aos Persas, seria impossível para as cidades sírias. Em Early Civilizations - Ancient Egypt in Context.

(5) Manfred BIETAK, «Hyksos», pp. 136-143.

(6) Fluxo agravado neste período devido a uma seca prolongada que atingiu o Sinai e a região cananaica. Donald B. REDFORD, Egypt, Canaan and Israel in Ancient Times.

(7) Geraldo Coelho DIAS, "O nome de Israel na estela do faraó Merenptah».

(8) James K. HOFFMEIER, Israel in Egypt, p. 117.

(9) James K. HOFFMEIER, op. cit., p. 116.

(10) “Exodus I-II» em Vetus Testamentum 13, pp. 408-418.

(11) “lkw und Ramses-stadt", em Vetus Testamentum 15, pp. 35-38.

(12) "IS it possible to write a History of Ancient Israel?", em Scandinavian Journal of the Old Testament 8.

(13) Ainda assim, Bryant G. WOOD alerta para a possibilidade de anacronismo na referência bíblica à cidade, utilizando um nome posterior, sobretudo porque os limites desta invadiam o território de Auaris (a actual Tell El-Dab'a), o que pode ter gerado alguma confusão.

(14) Eric UPHILL, Egyptian Towns and Cities, p. 48.

(15) Edgar B. PUSCH, "Piramesse», pp. 48-50.

(16) O mesmo autor chega a considerar a hipótese Sile em "Nebesheh and Defenneh", BIFAO 96 f., II, p. 29.

(17) "Tanis and Pi-Ra'messe: a retraction", em Journal of Egyptian Archaeology 19.

(18) Pierre MONTET, Egypt and the Bible - People, Places and Customs, pp. 48-68.

(19) Ibidem p. 123.

(20) Sobre este tema: “(...)nenhum dos edifícios até agora escavados (em Tânis) provou, de modo convicente, ter sido construído antes do reinado de Psusennes I, da XXI dinastia, sendo, portanto, forçoso concluír que todos os vestígios da época dos Ramséssidas ou de épocas anteriores foram trazidos de outros lugares.", John BAINES e Jaromir MÁLEK, Egipto - Deuses, Templos e Faraós, Lisboa: Círculo de Leitores, 1991, p. 177.

(21) Edgar B. PUSCH, “Qantir/Pi-Ramsés", pp. 647-649.

(22) Ibidem.

(23) Edgar B. PUSCH, «Piramesse», pp. 48-50.

(24) Eric UPHILL, op. cit., p. 64.

(25) Algo que confirma as informaçöes do Papiro Anastasi 4-5: «Her west is the House of Amen, the south is the House of Seth, Astarte is situated in her east and Wadjet is in her north", citação contida em Edgar B. PUSCH e Anja HEROLD, op. cit.

(26) Primeiro vestígio do género no Egipto, segundo Edgar B. PUSCH e Anja HEROLD, op. cit. 
(27) Edgar B. PUSCH e Anja HEROLD, op. cit.

(28) Como três fornalhas de tipo "cruzado", medindo 9 metros de altura por 8 metros de largura.

(29) Edgar B. PUSCH, op. cit.

(30) John S. HOLLADAy, «Pithom», pp. 50-53.

(31) The store city of Pithom and the route of the Exodus, Londres: Egyptian Exploration Society, 1883.

(32) T. E. PEET, Egypt and the Old Testament.

(33) Journal of Near Eastern Studies 27, pp. 291-316.

(34) Op. cit.

(35) John S. HOLLADAY, «Tell El-Maskhuta", pp. 786-789.

(36) Barbara J. SIVERTSEN, The Parting of the Sea. How Volcanoes, Earthquakes, and Plagues Shaped the Story of Exodus, pp. 20-21.

(37) John S. HOLLADAY, art. cit.

(38) "Glass fabrication illustrated at Qantir was done in a multi-step process. First, the workers ground quartz-rich sand into a fine powder and melted it in ceramic vessels lined with lime and constructed with a narrow opening. These vessels were heated to a temperature of between 900 and 950 degrees Centigrade. Once cooled, the raw glass was popped out of the jars and crushed again, then washed to remove the impurities. Next, the refined glass powder was mixed with coloring agents and poured into cylindrical crucibles. These crucibles were heated to between 1000-1100 degrees C, producing intensively colored disk-shaped glass ingots. These monochromatic ingots were then shipped to artisans who used the ingots to make polychrome glass vessels, faience, and glass slips. Ingot colors produced at Piramesses included clear, red, cobalt blue and a transparent purple color." Thilo REHREN e Edgar B. PUSCH, "Late Bronze Age Glass Production at Qantir-Piramesses, Egypt", em Science 17, Junho de 2005.

\section{Bibliografia}

\section{Fontes}

Bíblia Sagrada, 16.ª ed., Lisboa: Difusora Bíblica, 1992

\section{Bibliografia geral}

Luís Manuel de ARAÚJO, "Tânis", em Dicionário do Antigo Egipto, Lisboa: Editorial Caminho, 2001, pp.

John BAINES e Jaromir MÁLEK, Egipto - Deuses, Templos e Faraós, Lisboa: Círculo de Leitores, 1991

Manfred BIETAK, "Hyksos", em Donald B. Redford (dir.), Oxford Encyclopedia of Ancient Egypt, vol. II, Oxford: Oxford University Press, 2001 
Geraldo Coelho DIAS, "O nome de Israel na estela do faraó Merenptah" em Didaskalia, vol. 35, Lisboa: Universidade Católica Portuguesa, 2005

Erik HORNUNG, History of Ancient Egypt, Edimburgo: Edinburgh University Press, 1999

Herman KEES, Ancient Egypt: a cultural topography, Chicago, Londres: The University of Chicago Press, 1961

Joseph MODRZEJEWSKI, The Jews of Egypt, from Ramses II to Emperor Hadrian, Princeton, New Jersey: Princeton University Press, 1995

Pierre MONTET, Egypt and the Bible - People, Places and Customs, Philadelphia: Fortress Press, 1968

José das Candeias SALES, "Líbios", em Dicionário do Antigo Egipto, Lisboa: Editorial Caminho, 2001, pp. 495-497

Barbara J. SIVERTSEN, The Parting of the Sea - How Volcanoes, Earthquakes, and Plagues Shaped the Story of Exodus, Princeton: Princeton University Press, 2009

Bruce TRIGGER, Early Civilizations - Ancient Egypt in Context, Cairo: The American University Press in Cairo, 1993

\section{Bibliografia específica}

John S. HOLLADAY, «Pithom", em Donald B. Redford (dir.), Oxford Encyclopedia of Ancient Egypt, vol. III, Oxford: Oxford University Press, 2001

John S. HOLLADAY, "Tell el-Maskhuta", em Kathryn A. Bard (dir.), Encyclopedia of Archaeology of Ancient Egypt, Londres, Nova lorque: Routledge, 1999

James K. HOFFMEIER, Israel in Egypt, Nova Iorque, Oxford: Oxford University Press, 1996

Edgar B. PUSCH e Anja HEROLD, "Qantir/Pi-Ramses", em Kathryn A. Bard (dir.), Encyclopedia of Archaeology of Ancient Egypt, Londres, Nova lorque: Routledge, 1999

Edgar B. PUSCH, "Piramesse", em Donald B. Redford (dir.), Oxford Encyclopedia of Ancient Egypt, vol. III, Oxford: Oxford University Press, 2001

Eric UPHILL, Egyptian Towns and Cities, Buckinghamshire: Shire Publications, 2001

Bryant G. WOOD, "The Royal Precint at Ramesses", em Bible and Spade, vol.17, n. 4, 2004 


\section{ANEXO}

Plano do núcleo urbano de Pi-Ramsés e hipóteses para parte da cidade de Auaris, na zona sudoeste. Retirado de UPHILL, Egyptian Towns and Cities, p. 63

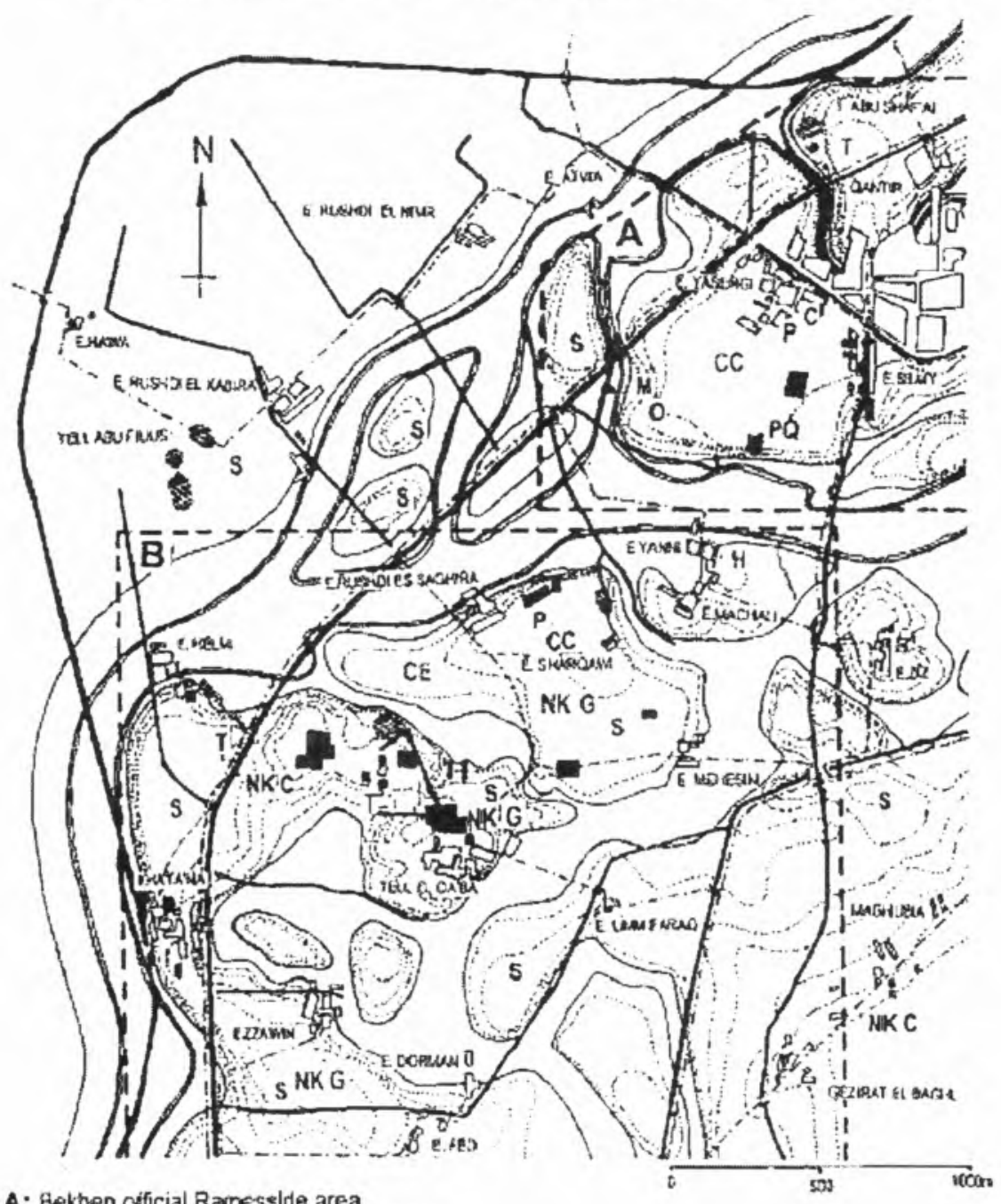

A: Bekhen cificial Rarnessilde area

B: Avaris area later House of Seth quarter

Uh vages 8 larms \& Tet siles
streets \& lracks axcaration sites
canids
$S$ setrement
P pace
$M$ soldiers
6 garden
NK New Kangoiom
C cemelery
$P Q$ palace quanes 0 officia's
H habou enclosure
LP Lale Perod
$T$ lemple
CC cilycone CE cily extension 